\title{
Astrocytes Regulate Microglial Phagocytosis of Senile Plaque Cores of Alzheimer's Disease
}

\author{
David A. DeWitt, ${ }^{*},{ }^{\prime} 1$ George Perry, $\uparrow$ Mark Cohen, $\uparrow$ Catherine Doller,* and J erry Silver* \\ *Department of Neurosciences and †I nstitute of Pathology, Case Western Reserve University, 10900 Euclid Avenue, Cleveland, Ohio 44106
}

Received September 18, 1997; accepted October 24, 1997

\begin{abstract}
We have developed an in vitro model in which isolated senile plaque (SP) cores are presented to rat microglial cells in culture. Microglia rapidly phagocytosed, broke apart, and cleared SP cores. However, when cocultured with astrocytes, microglial phagocytosis was markedly suppressed, allowing the SPs to persist. Suppression of phagocytosis by astrocytes appears to be a general phenomena since microglia in the presence of astrocytes showed reduced capacity to phagocytose latex beads as well. The astrocyte effect on microglia is related in part to a diffusible factor(s) since astrocyte- but not fibroblast-conditioned media also reduced phagocytosis. These results suggest that while microglia have the capacity to phagocytose and remove SPs, astrocytes which lie in close association to microglia may help prevent the efficient clearance of SP material allowing them to persist in Alzheimer's disease. $\odot$ 1998Academic Press
\end{abstract}

Key Words: beta amyloid; macrophages; neurodegenerative diseases; CNS-injury; debris removal; reactive gliosis.

\section{INTRODUCTION}

Amyloid $\beta(A \beta)$ accumulation in senile plaques (SP) is considered a key step in the pathogenesis of Alzheimer's disease (AD) (55). This contention is supported by numerous molecular and genetic studies linking mutations in the $\beta$-protein precursor ( $\beta P P)$ to increased production of $A \beta(8,19,46,55,64)$. While most studies have focused on $A \beta$ formation, maintenance of the SP depends not only on factors which promote $A \beta$ production, but also on factors which hinder efficient clearance (31). Therefore, SP maintenance is likely to be a complex interaction of $A \beta$ with the surrounding dystrophic neurites (12), processes of reactive astrocytes (9, $42,52)$, and activated microglia $(12,28,34,43,49)$. As the resident macrophages of the brain $(21,62,68)$,

\footnotetext{
${ }^{1}$ Present address: Department of Biology and Chemistry, Liberty University, 1971 University BIvd., Lynchburg, VA 24502.
}

microglia are likely candidates in A $\beta$ catabolism. However, even though activated microglia are a common component of SPs, there is little evidence for efficient $A \beta$ removal by them in $A D(16,27)$.

The efficiency of microglial phagocytosis and debris removal seems to be related to their state of activation. Early in development or following certain types of injury in the adult when debris removal is rapid, microglia have a round or ameboid morphology and express high levels of various macrophage markers (4, $6,13,15,20,22,24,30,32,33,35,38,45,60,63,68)$. In contrast, so-called "resting" microglia in the adult CNS have a ramified or process bearing morphology with a small cell body, low levels of macrophage markers (13, $45,62,72)$, and poor phagocyticability $(7,13,23,50,51$, 69). Following axotomy via a nonpenetrating injury, e.g., dorsal rhizotomy or infection, resting microglia become activated $(5,13,20,68)$. Although such activated cells express high levels of macrophage markers, they remain process bearing and continue to show limited phagocytosis $(13,20,37)$. The cell processes often found on microglia associated with SP are similar to those showing limited phagocytic activity $(28,34)$. Yet microglia in the adult CNS are able to phagocytose debris following certain severe insults in the adult, e.g., a penetrating injury or stroke, $(20,22,24)$. Indeed, when infarcts occur in AD brain, SP actually can be rapidly removed by microglia that transform into macrophages (70; P. Gambetti, personal communication). Understanding the mechanism(s) that modulate microglial activation and clearance of $A \beta$ is critical to understanding SP homoeostasis.

Since astrocytes can modify microglial/monocyte be havior $(1,26,39,44,58,65,67)$, we examined the role of astrocytes as potential modulators of microglial interactions with SPs in vitro. We found that purified rat microglia with a round, macrophage-like morphology rapidly phagocytose and clear SP cores. In contrast, when cocultured with rat cortical astrocytes microglia had a process bearing morphology and phagocytosis was dramatically suppressed. Therefore, SP persistence in vivo may be the result of a complex interplay that occurs between glial cells associated with the SP. 


\section{METHODS}

I solation of SenilePlaque Cores

SP cores were isolated using a modification of the procedure of Selkoe et al. (56). Portions of frontal and temporal lobe from three patients with confirmed, severe Alzheimer's disease were obtained at autopsy and frozen. The meninges and large blood vessels were removed along with large portions of white matter. Grey matter was finely minced and stirred for $2 \mathrm{~h}$ in $2 \%$ SDS, $1 \mathrm{mM}$ Tris ( $\mathrm{pH}$ 7.6) to a final volume of $5 \times$. Tissue was homogenized by 20 passages in a Dounce homogenizer (A pestle). The homogenate was brought to $97^{\circ} \mathrm{C}$ for $10 \mathrm{~min}$, sieved through $110-\mu \mathrm{m}$ nylon mesh, and centrifuged at $300 \mathrm{~g}$ for $30 \mathrm{~min}$ to pellet the SP corecontaining fraction. The samples were then washed in (0.1\% SDS, $\left.150 \mathrm{mM} \mathrm{NaCl}, 0.02 \% \mathrm{NaN}_{3}\right)$ and centrifuged again at $300 \mathrm{~g}$ for $10 \mathrm{~min}$. The samples were sieved through a 35- $\mu \mathrm{m}$ nylon mesh and then applied to a noncontinuous sucrose gradient (1.2 M, 1.4 M, 1.6 M, $1.8 \mathrm{M}$ sucrose) and centrifuged again at $72,000 \mathrm{~g}$ for 60 min. All interfaces were collected, pelleted, and washed $3 \times$ with $1 \mathrm{mM}$ Tris (pH 7.6), 0.1\% SDS to remove sucrose. Most of the SP cores as well as some lipofuscin were at the $1.4 \mathrm{M}-1.6 \mathrm{M}$ interface as demonstrated by Congo red birefringence. To enhance the purity of the SP cores as well as to remove small or broken cores and clumps, a Bectin-Dickinson FACStar Plus was used. SP cores were sorted by fluorescence and size (56), with a flow rate of 1000 particles per second. SP cores were stored at $4^{\circ} \mathrm{C}$ until use.

\section{I mmunocytochemistry}

Cells and SP attached to coverslips were fixed in $2 \%$ paraformaldehyde in 1 M PBS, $\mathrm{pH}$ 7.2, for $1 \mathrm{~h}$ and rinsed with $1 \mathrm{M}$ PBS. Endogenous peroxidase activity was blocked with $3 \%$ hydrogen peroxide for $30 \mathrm{~min}$. The coverslips were further blocked with $10 \%$ normal goat serum for $30 \mathrm{~min}$ prior to addition of primary antibodies or lectin. The lectin $G$. simplicifolia (I solectin $B_{4}$, biotin conjugated, Sigma) was specific for microglia and did not bind to astrocyte cultures (61). Additionally, ED1 and OX-42 (Chemicon) were used as markers of microglia (45). Cellular purity was assessed by using phase microscopy and antisera to GFAP (Accurate), an astrocyte marker, and O1, an oligodendrocyte marker (gift of Robert Miller). SP cores were identified with the monoclonal 4G8 (36) or antisera toA $\beta$. Primary antibodies and lectin $(20 \mu \mathrm{g} / \mathrm{ml})$ were incubated overnight at $4^{\circ} \mathrm{C}$. The peroxidase anti-peroxidase method (59) with diaminobenzidine as a cosubstrate was used to visualize the immunoreaction. Biotinylated lectin and ED1 were visualized with Vectastain ABC streptavidinalkaline phosphatase (Vector Labs) with Fast Blue as a chromagen.

\section{Microglia Cultures}

Microglia were obtained using a modification of the procedure of Giulian and Baker (23). Mixed cultures were prepared from the cortex of PO Sprague-Dawley rat pups, and grown in poly-L-lysine-coated flasks with DMEM (Gibco) containing 20\% fetal calf serum. After 6- 7 days, the cultures were placed in an orbital shaker at $37^{\circ} \mathrm{C}$ for $1 \mathrm{~h}$. Microglia were separated by collecting the media, since astrocytes and other cells remain attached to the substrate. Microglia were seeded onto poly-lysine-coated coverslips and after $1 \mathrm{~h}$, when a majority of microglia had adhered, the media was changed to further eliminate contaminating, nonadherent cells. Microglia obtained in this manner were consistently $>95 \%$ pure. Unless indicated, approximately 2-3 × $10^{4}$ cells per well were grown in 24-well Falcon plates.

\section{Astrocyte Cultures and Conditioning}

Astrocytes were obtained from neonatal rat pups. Mixed glial cultures were prepared as indicated above except they were grown in DMEM with $10 \%$ FCS for 2 weeks to allow for growth of astrocytes. Microglia and other cells were removed through shaking. About $5 \times$ $10^{4}$ astrocytes per well were grown with SP cores for 1 week prior to the addition of microglia to determine the effects of astrocyte conditioning/coculture. Astrocyteconditioned media was collected after 4 days in culture and applied to mi croglia cultures $1-2 \mathrm{~h}$ after seeding to determine the effects of soluble, astrocytic factors.

\section{Fibroblast Cultures}

Fibroblasts were obtained from the meninges which were stripped from the neonatal rat brain, diced with a razor blade, and added to poly-lysine-coated culture flasks with DMEM and $10 \%$ FCS. Fibroblasts adhered to the flask and the media was changed after 1 day to remove large aggregates of cells. Fibroblast-conditioned media was also obtained after 4 days.

\section{Quantification of SenilePlaqueCores}

The fate of SP cores was assayed by binding 1-2 $\mu$ l of SP core stock solution (Approximately $500 \pm 30$ SD) to $15-\mathrm{mm}$ glass coverslips previously coated with poly-LIysine. These were incubated in the presence of 2-3 $\times$ $10^{4}$ microglial cells per well in a 24-well plate. At various time points, the coverslips were fixed in $2 \%$ paraformal dehydeand processed for immunocytochemistry. At the time of fixation, and during all media changes, the media was collected and frozen for later analysis. Four coverslips were used for each time point. This paradigm was repeated for two complete sets yielding a total of eight coverslips per time point.

Following immunocytochemistry and Congored stain- 
ing for $A \beta$, the SP cores remaining were counted on a Zeiss Axiophot microscope using the $20 \times$ objective and the $2 \times$ optivar. Lectin/alkaline phosphatase staining was used to determine if microglia surrounded SPs (intracellular) or were either not associated with microglia or simply in close juxtaposition (extracellular). A $\beta$ immunoreactive material within microglia which appeared as condensed, small vesicles within the cell (>5 $\mu \mathrm{m}$ total diameter) was scored as 1 SP. Multiple SP cores were scored as such only when each of the $A \beta$ aggregates was $\sim 10 \mu \mathrm{m}$ diameter. In parallel cultures, SP cores were incubated in media alone or astrocyte cultures in the absence of microglia. Spent media was saved and analyzed for intact SP cores by centrifugation at $5000 \mathrm{~g}$ for $10 \mathrm{~min}$. The pelleted material was smeared and stained with Congo red solution and viewed under cross-polarized light.

\section{Phagocytosis of Latex Beads}

Latex beads (Sigma) of the approximate diameter as SP cores (11 $\mu \mathrm{m}$ diameter) were used to compare phagocytosis of SP cores versus that of dissimilar material as well as to determine the percentage of phagocytic cells in conditioned media. Prior to use, 500 $\mu \mathrm{L}$ of a $2.5 \%$ suspension of beads was activated with borate buffer (pH 8.0) and incubated with $300 \mu \mathrm{g} / \mathrm{mL}$ bovine serum al bumin for $2 \mathrm{~h}$ at $20^{\circ} \mathrm{C}$. The beads were rinsed three times with Tris- $\mathrm{HCl}, \mathrm{pH} 7.2$, and stored in Tris buffer, at $4^{\circ} \mathrm{C}$ until use.

Microglia were seeded at approximately $3 \times 10^{4}$ cells per well in $1 \mathrm{ml}$ of DMEM with $10 \% \mathrm{FCS}$. After $2 \mathrm{~h}$, the media was replaced with fresh media or that conditioned for 4 days by either astrocytes or fibroblasts (which had been passed through a 0.2- $\mu$ m filter). After $24 \mathrm{~h}, 1-\mu \mathrm{l}$ (approximately $10^{5}$ ) beads were added to each well. On day 2 , the percentage of cells phagocytosing beads was determined. The first 100 randomly selected cells were counted by a "blind" observer and scored as having 0,1 , or $>1$ bead per cell.

Latex particles of $0.5 \mu \mathrm{m}$ diameter (Polysciences) were used to quantitate the extent and rate of phagocytosis. Since these smaller beads were supplied in excess and microglia could phagocytose $>10$ beads (rather than $1-2$ seen with $11-\mu$ m beads), they serve as a better index for the extent of phagocytosis and kinetic analysis than the larger beads. After a 24-h incubation of the microglial cells with astrocytes or astrocyte-conditioned media, latex particles were added. The cells

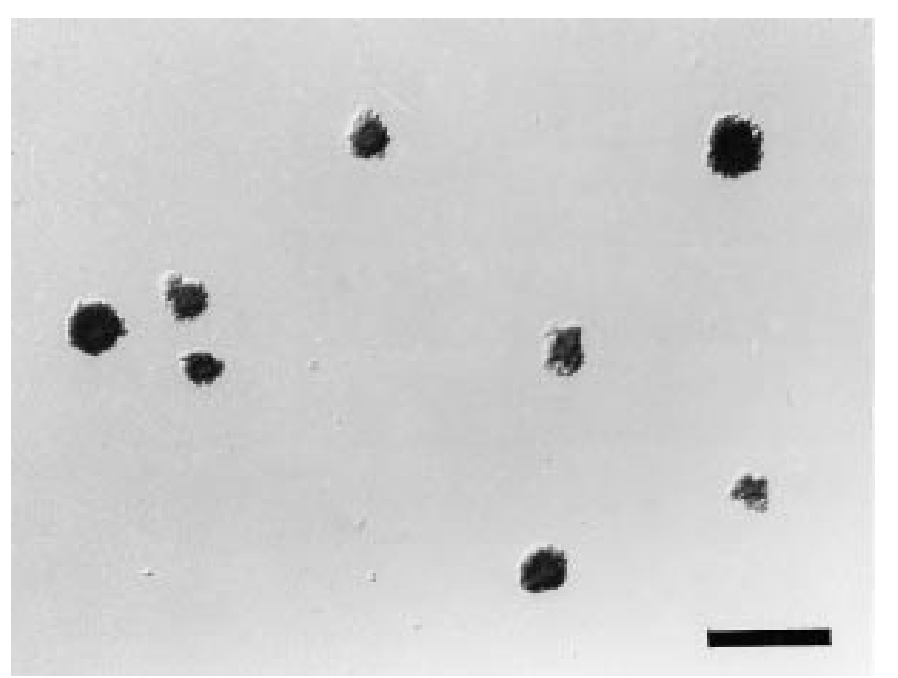

FIG. 1. I solated senile plaque cores following FACS sorting and immunocytochemistry for $A \beta$. Scale bar, $50 \mu \mathrm{m}$.

were fixed after 6 or $24 \mathrm{~h}$ and analyzed. The total number of beads within randomly selected microglia was determined.

\section{Electron Microscopy}

Cultures were fixed in 4\% paraformal dehyde with 3\% glutaral dehyde, rinsed, and postfixed with $1 \%$ osmium tetroxide in $0.1 \%$ sodium cacodylate buffer. The coverslips were then dehydrated in ethanol followed by infiltration in Spurr medium. Thin sections were made, stained with lead citrate and uranyl acetate, and observed on a J EOL 100 el ectron microscope.

\section{RESULTS}

\section{I solation of SP Cores for Usein an in Vitro Mode}

SP cores from AD brain were isolated by the method of Selkoe et al. (56), which yields a population with a fairly uniform diameter (from 5 to $20 \mu \mathrm{m}$ ). They were Congo red positive, displaying the characteristic applegreen birefringence in a Maltese cross-pattern under polarized light and were also $A \beta$ immunoreactive (Fig. 1). This morphology is virtually identical to SP cores in AD brain. When placed in DMEM/F 12 media alone, over $95 \%$ of SP cores remain bound to coverslips and intact for at least 30 days.

FIG. 2. In vitro, SP cores (c, brown) are phagocytosed by rat cortical microglia (blue, GS1B4 isolectin) (A) and subsequently appear as numerous small vesicles containing $A \beta$ (arrow) $(B)$. Scale bar, $10 \mu \mathrm{m}$.

FIG. 6. In vivo, astrocytes show increased GFAP immunoreactivity (brown) in processes surrounding SP cores (c, core) (A). In vitro, rat astrocytes (GFAP, brown) also surround SP cores (blue) (B). Microglia (HLADR, purple) associated with SP cores (brown) in vivo are often ramified (C). Similarly, microglia (ED1, blue) cultured on monolayers of astrocytes (unstained, arrowheads) have a ramified morphology even near SP cores (brown) (D). Note: in neither case is there evidence of phagocytosis of SP cores. Scale bars, $30 \mu \mathrm{m}$. 

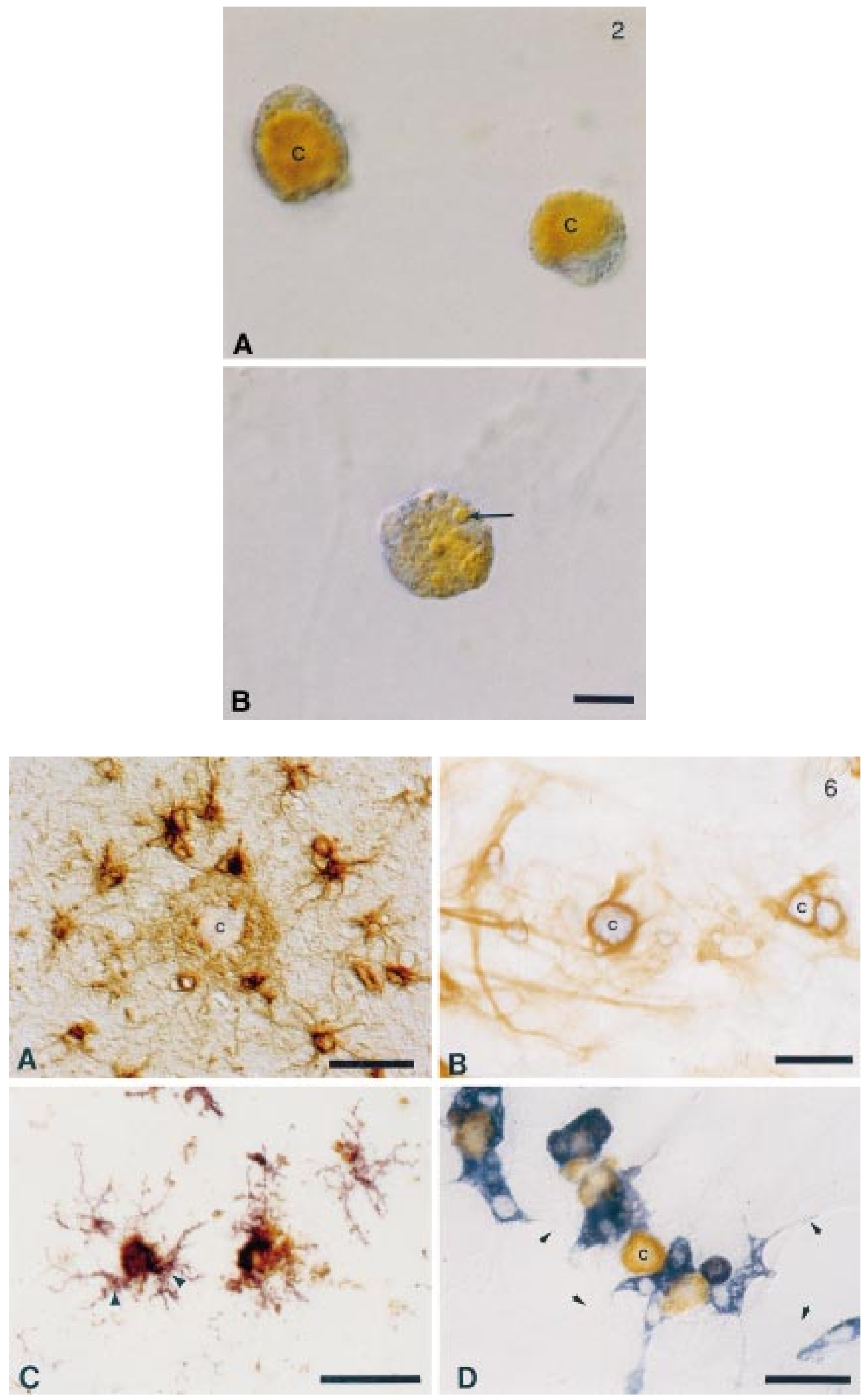


\section{Microglia Phagocytoseand DegradeSP Cores}

Rat microglial cells have the ability to phagocytose $\mathrm{SP}$ cores and began to internalize them within $2 \mathrm{~h}$ after plating. Although most microglia contained 1 core per cell (Fig. 2A), a few cells phagocytosed multiple cores (not shown). With extended time, the SP cores were broken apart and incorporated into smaller intracellular vesides (Fig. 2B) a phenomenon that was also observed ultrastructurally (see below). Most cells contained a singleA $\beta$ containing vesicle (roughly 6-12 $\mu \mathrm{m}$ ). Others had numerous small (1-2 $\mu \mathrm{m}) A \beta$ containing vesicles. The number of cells with these "broken" cores was low, suggesting that SP cores are rapidly cleared once they have been partitioned into smaller vesicles.

Electron microscopy verified that the SP cores were intracellular (Fig. 3A). At early time points, intact SP
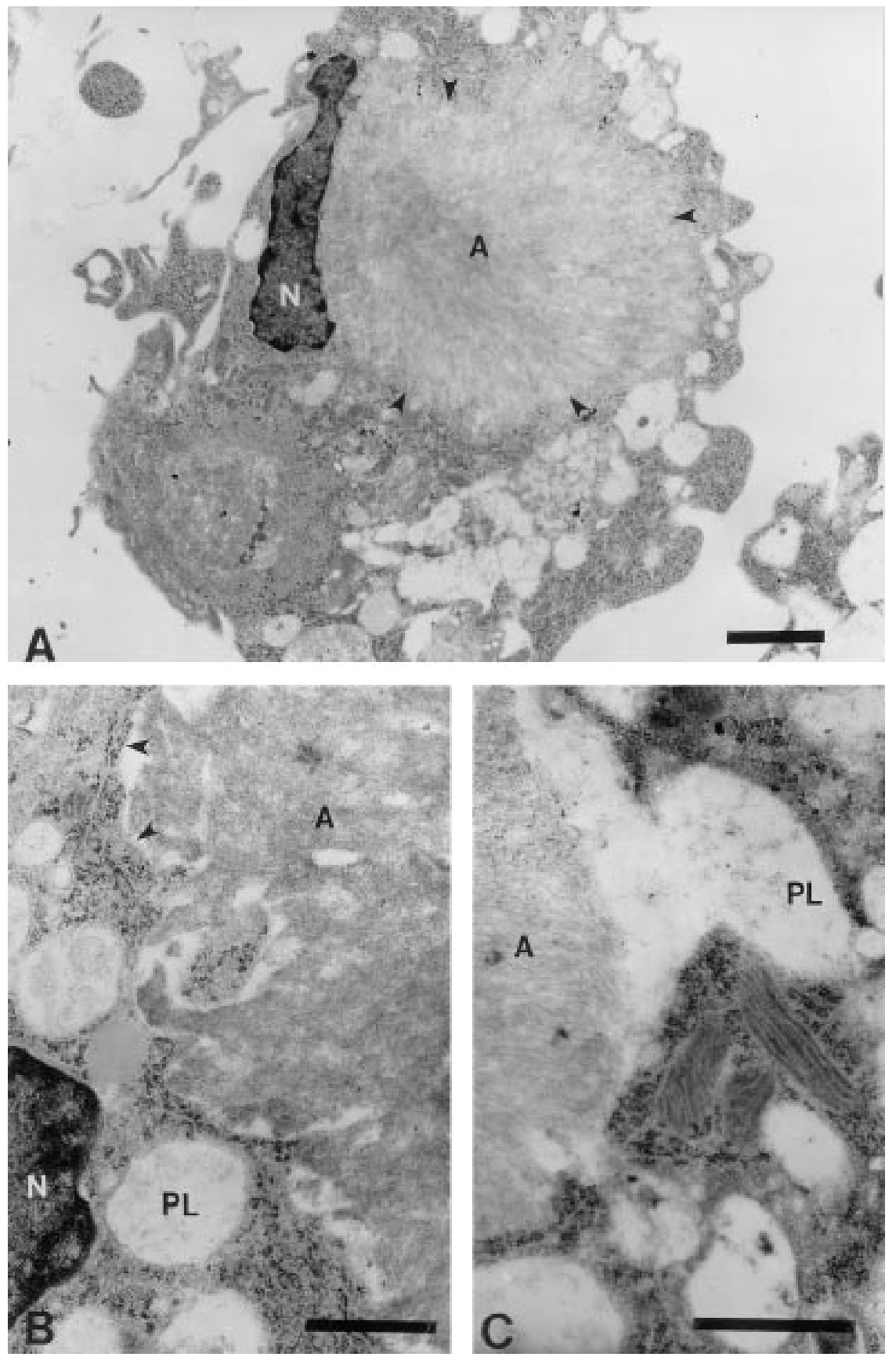

FIG. 3. Ultrastructural examination of internalized SP cores shows $A \beta$ fibrils ( $A$, arrowheads) (A) within a membrane bounded vesicle (arrowheads) (B). Phagolysosomes (PL) could be seen fusing with the SP containing vesicle (C). N, nucleus. (A) Scale bar, 2 Hm. (B, C) Scale bar, $1 \mu \mathrm{m}$. 
cores could be observed in apparent membrane bounded structures residing entirely within the cell (Fig. 3B). The SP cores occupied most of the cytoplasmic space, displacing the nucleus to one side. Phagolysosomes, characteristic of microglia, could be seen fusing with the SP core containing vesicle (Fig. $3 \mathrm{C}$ ), suggesting that lysosomal enzymes may be involved in SP breakdown.

\section{Temporal Distribution of SP CorePhagocytosis and Breakdown}

To determine the kinetics of SP core clearance from microglial cultures, we examined their temporal distribution. Extracellular SP cores decreased continuously and exponentially during the culture period, consistent with rapid phagocytosis by microglia (Fig. 4A). In conjunction, the number of intracellular SP cores increased steadily within the first $24 \mathrm{~h}$, but then stabilized for the next 7 days in culture (Fig. 4B), and then decreased.

After 3 days in culture, the total number of SP cores (extracellular and intracellular combined) decreased exponentially; less than $10 \%$ remained by day 30 (F ig. 4C). This distribution of SP cores is consistent with phagocytosis, internal processing leading to breakdown, and subsequent turnover or removal of SP from the cell.

\section{Phagocytosis May Bethe RateLimiting Step}

In order to determine if the rate-limiting step in SP core clearance is the rate of phagocytosis or subsequent breakdown, the rate of SP core clearance was followed for a range of microglial cell densities. At higher cell densities, nearly $100 \%$ of the SP cores were phagocytosed within $24 \mathrm{~h}$ while with low cell densities it was $<60 \%$ over the same time period. The initial rate of SP core dissolution was dependent on the number of cells per well (Fig. 5A), suggesting that phagocytosis is a rate-limiting step in SP core clearance with a minimum SP core half-life of 2.4 days (Fig. 5B). However, even with maximum cell density (100,000 cells per well) and virtually all of the SP cores internalized within hours, there was a small fraction of cores which persisted intracellularly for at least 14 days. It is unclear whether this is a subset of resistant SP cores or a subgroup of microglia with less efficient digestive capacity.

\section{Response of Glial Cells to SP Cores in Vitro}

In order to mimic the cellular complexity of the SP we presented isolated SP cores to microglia in mixed glial cultures. Rat cortical astrocytes were grown on SP cores which had been bound to coverslips. Astrocytes wrapped processes around the SP cores but did not phagocytose them, a situation that is reminiscent of astrocytes associated with SPs in AD brain (compare Figs. $6 \mathrm{~A}$ and $6 \mathrm{~B}$ ). These cells appeared to adopt a
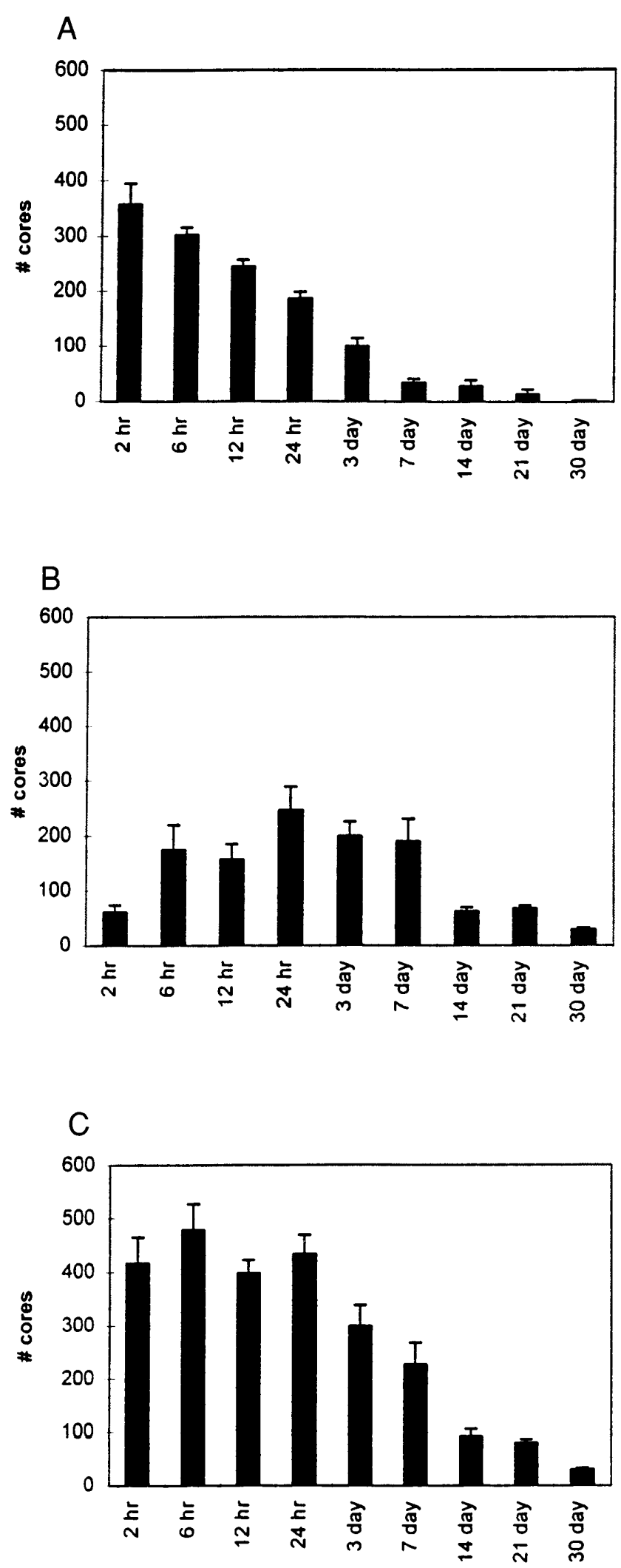

FIG. 4. Time course of microglial SP phagocytosis expressed as extracellular (A), intracellular (B), and total SP cores (C). Each time point is an average from eight coverslips. 
reactive phenotype as indicated by their morphology and increased GFAP immunoreactivity (Fig. 6B) in the immediate vicinity of the SP core. SP cores were not toxic to astrocytes since these cells survived with SP cores through 30 days in vitro. Further, DIC microscopy and immunocytochemistry indicated that the astrocytes did not completely cover the SP cores but left them partially exposed providing a surface for microglial contact.

Microglia seeded onto an established monolayer of astrocytes with SP cores adopted a process bearing morphology even when in close contact with SP cores (Fig. 6D). The microglial processes were long and branched, consistent with previous studies which have shown that astrocytes induce microglial ramification
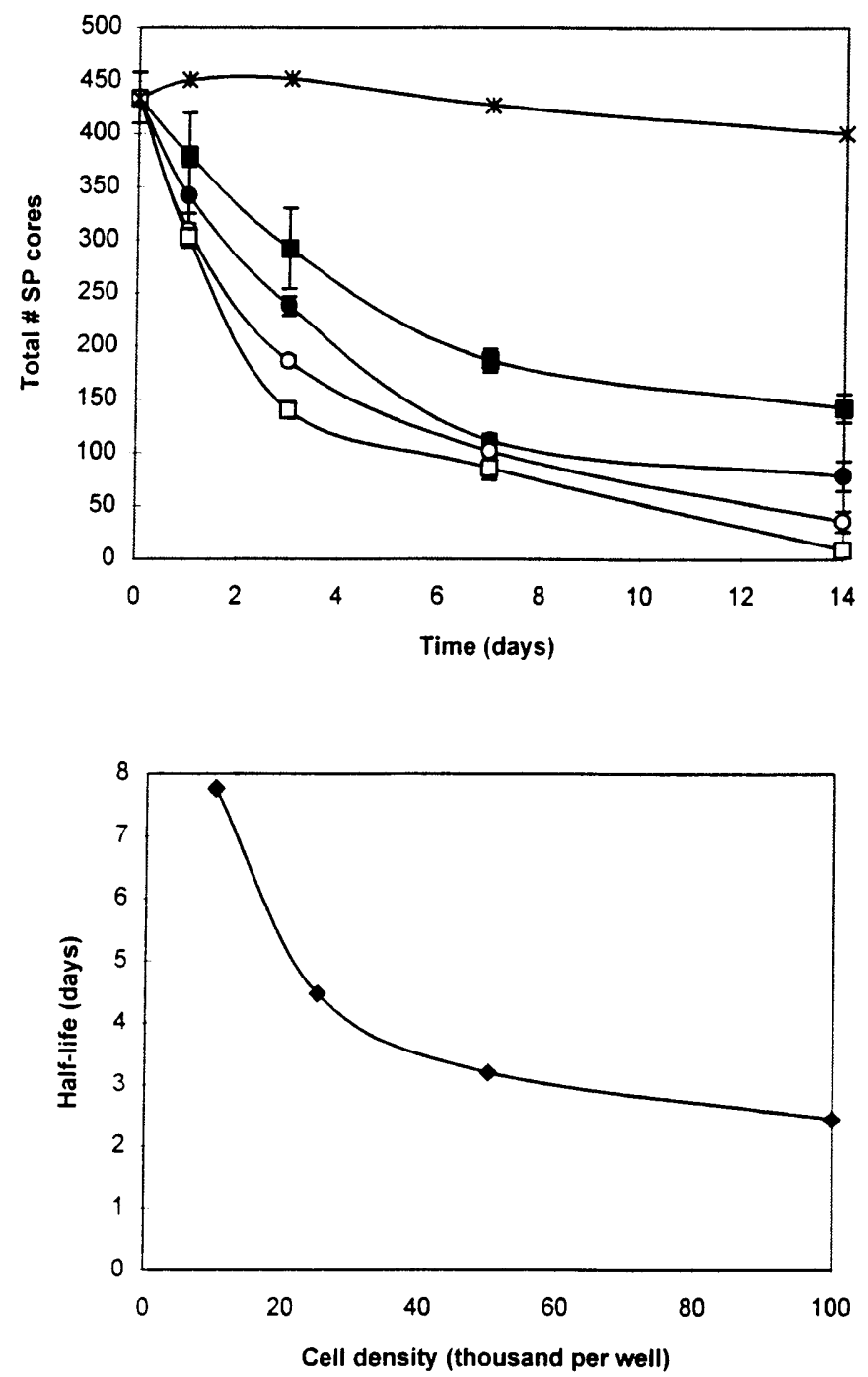

FIG. 5. SP core clearance was dependent on microglial density (A) as reflected in a decreasing half-life (B). In A, each time point represents an average from six coverslips from two experiments. (*no microglia; $\square, 1 \times 10^{3}$ cells/well; $0,2.5 \times 10^{3}$ cells/well; $\bigcirc, 5 \times 10^{4}$ cells/well; $\square, 1 \times 10^{5}$ cells/well.)

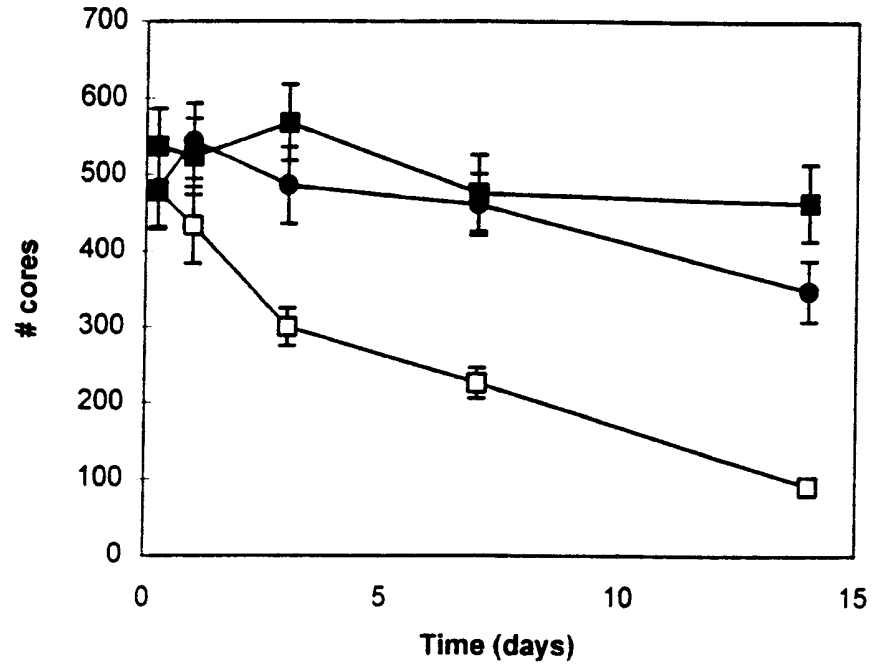

FIG. 7. In contrast with the clearance of SP cores by microglia, if SP cores were cultured with astrocytes for 7 days prior to addition of microglia virtually no SP cores were cleared. ( $\square$, microglia only; $\bullet$, microglia + astrocytes; $\mathbf{a}$, no microglia.)

(26, 39, 58, 65). During the 14-day period of the experiment, few microglia phagocytosed SP cores in the presence of astrocytes. Surprisingly, microglia often clustered tightly around the SP cores but, nonetheless, they did not phagocytose them (Fig. 6D). Both micro-

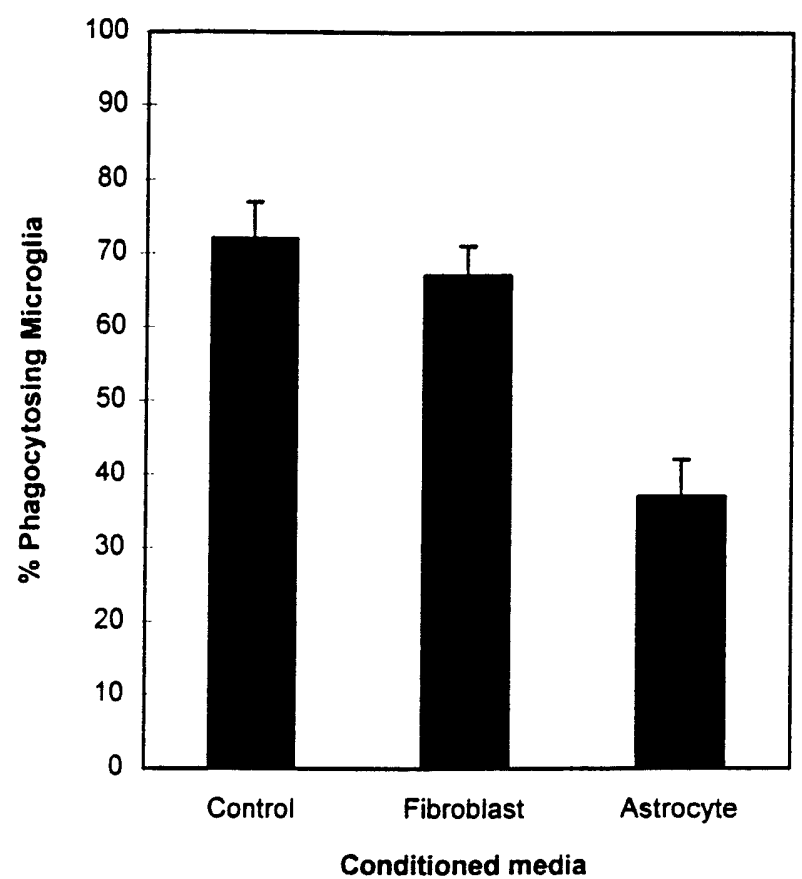

FIG. 8. Microglia were grown in astrocyte conditioned, fibroblast conditioned, or control media for $24 \mathrm{~h}$ prior to addition of polystyrene beads. Astrocyte-conditioned media reduces the percentage of microglia phagocytosing $11-\mu \mathrm{m}$ polystyrene beads compared to nonconditioned media or fibroblast conditioned media. Note: microglia which had phagocytosed a bead had a round morphology. (Representative data, $\mathrm{N}=6$, performed in triplicate.) 
glial clustering and their process bearing morphology are characteristics of microglia in AD brain (Fig. 6C). With extended time in coculture, some microglia did eventually phagocytose SP cores; however, the decreased phagocytosis of SP cores in the presence of astrocytes was reflected in their persistence. Time course experiments indicated the SP cores were not readily broken down or cleared from microglia cocultured with astrocytes (Fig. 7).

\section{Effect of Astrocytes/ Astrocytic Factors on Microgl ial Phagocytosis}

To determine whether astrocyte factors decrease microglial phagocytosis generally, we used $11-\mu \mathrm{m}$ latex beads as a model of SP cores but having the advantage that they cannot be broken down. While microglia readily phagocytosed these beads, neither astrocytes nor fibroblasts did. In cocultures, microglia growing on fibroblast monolayers quickly phagocytose the beads; however, microglia growing on astrocyte monolayers showed virtually no internalization of the beads. The ability of astrocytes to suppress phagocytosis is, in part, diffusible since the percentage of phagocytic microglia was significantly lower in astrocyte-conditioned media compared with fibroblast conditioned media (Fig. 8). In all cases, suppression of phagocytosis was temporally correlated with microglial transformation from a round to a ramified morphology. These results were consistent with other findings that ramified microglia have impaired phagocytic ability $(23,69)$ since microglia grown on astrocytes were ramified while those on fibroblasts were round.

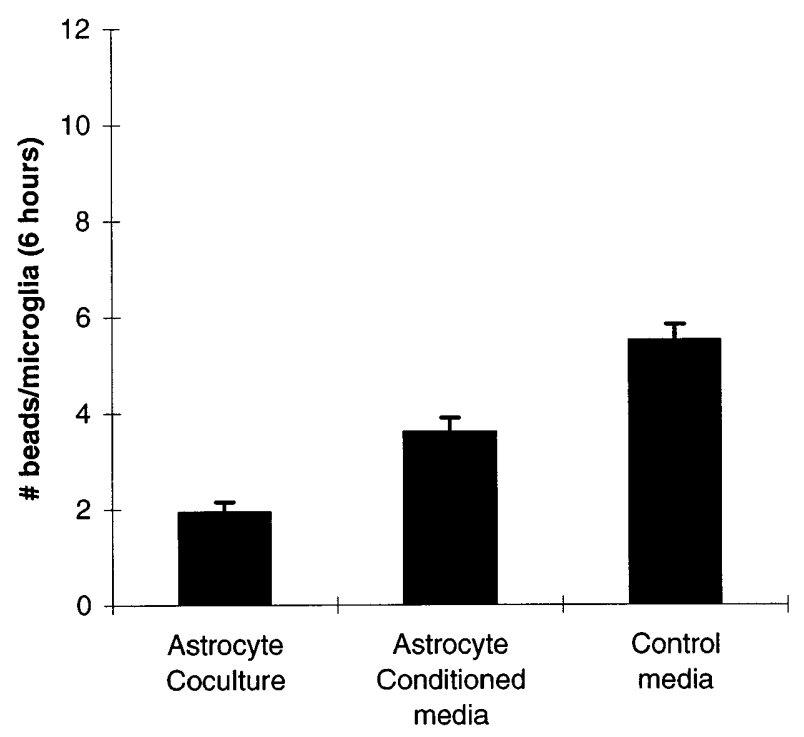

Culture Conditions
We further analyzed the effects of astrocytes on the extent and rate of microglial phagocytosis using $0.5-\mu \mathrm{m}$ latex particles. The smaller size allows the microglia to phagocytose numerous beads which provides a more precise evaluation of the kinetics of phagocytosis. Microglia were incubated for $24 \mathrm{~h}$ in the presence of astrocytes, astrocyte-conditioned media, or control media prior to addition of the latex particles. Astrocyte cocultures suppressed phagocytosis at least three-fold compared to control media. A similar, although less dramatic effect was also seen in astrocyte-conditioned media (Fig. 9A) after $6 \mathrm{~h}$. In both astrocyte cocultures and conditioned media, phagocytosis was still significantly suppressed after $24 \mathrm{~h}$; however, by this time, the differences between astrocyte coculture and astrocyteconditioned media were less obvious (Fig. 9B). While diffusible astrocytic factors appear to suppress microglial phagocytosis in general, direct astrocytic contact was clearly more effective in suppression of phagocytosis as well as induction of a ramified morphology (Fig. 10).

\section{DISCUSSION}

We have shown that microglial cells from rat cortex can rapidly phagocytose wholeSP cores. Once internalized, theSP cores were partitioned into smaller vesicles and cleared from the cell. However, when in the presence of astrocyte-conditioned media or especially when direct contact occurred between astrocytes and microglia, microglial phagocytosis was strongly suppressed with a coincident increase in their ramification. This suggests that both diffusible and astrocyte contact-

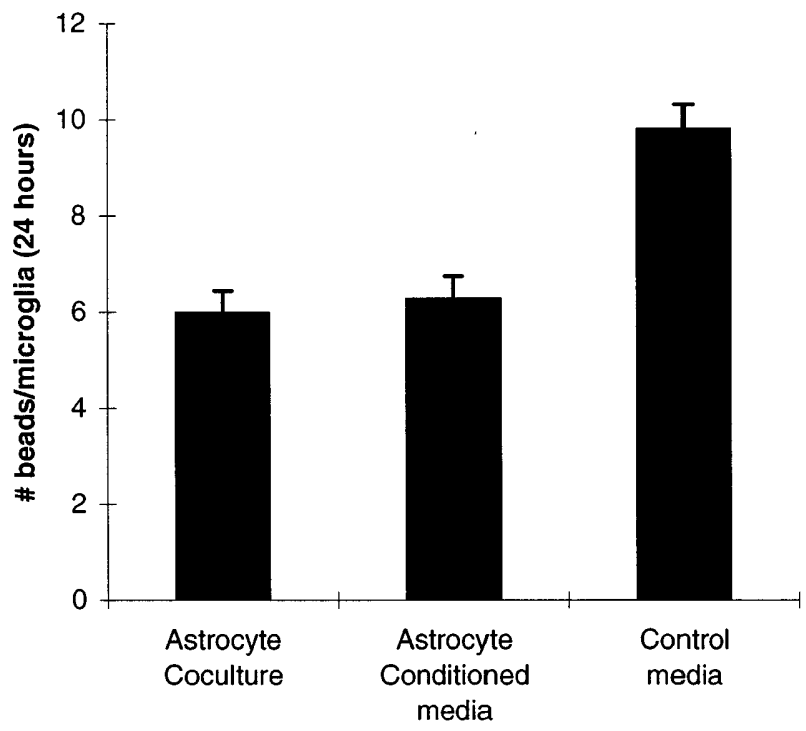

Culture Conditions

FIG. 9. Phagocytosis of $0.5-\mu \mathrm{m}$ latex particles conditioned for $24 \mathrm{~h}$ with astrocytes, astrocyte-conditioned media, or control media. After 6 $\mathrm{h}$, astrocyte-conditioned media suppresses microglial phagocytosis; however, not to the same extent as astrocyte cocultures until $24 \mathrm{~h}$ (B), while both are significantly less than control. (Representative data, performed in triplicate.) 

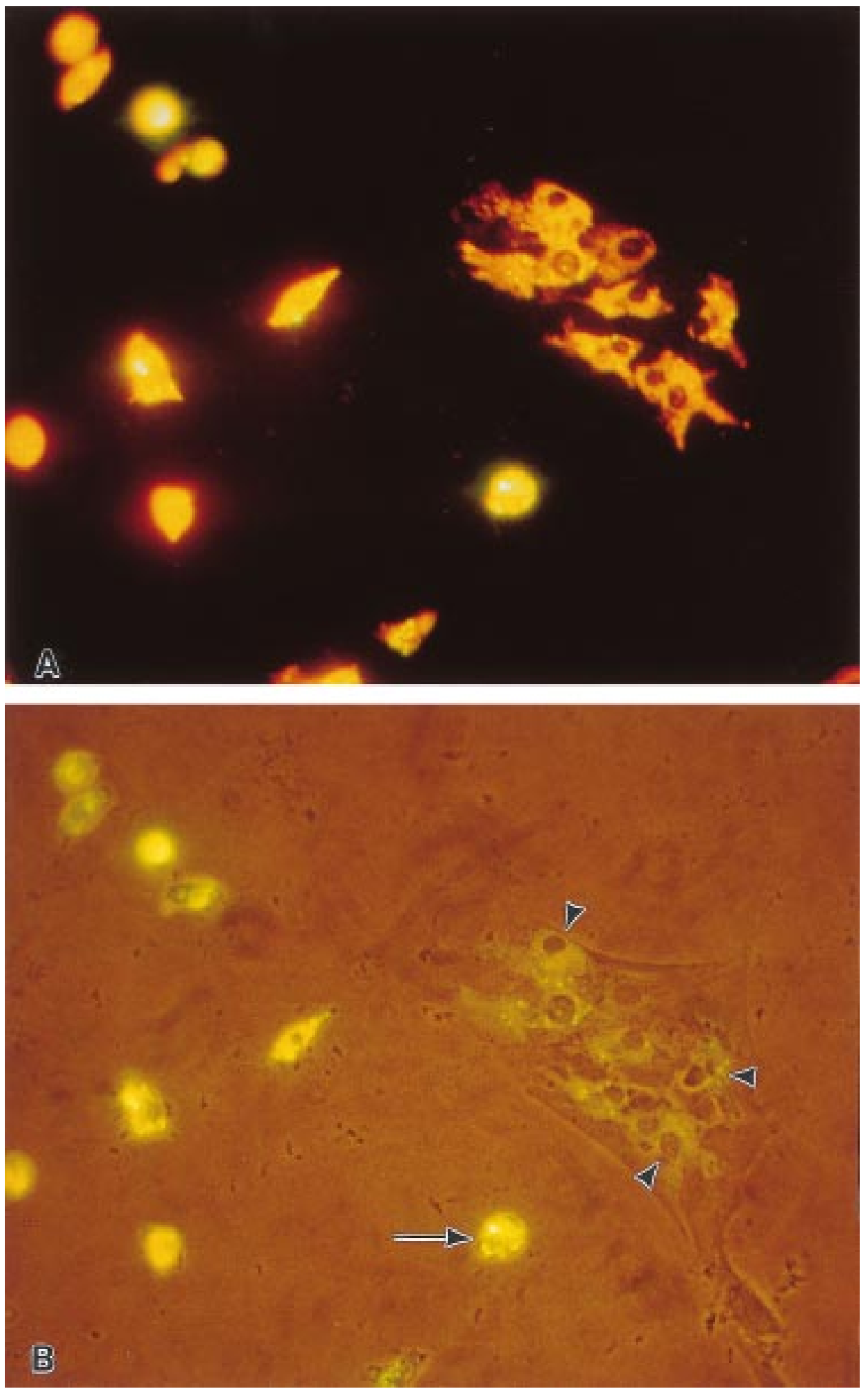

FIG. 10. As early as 1 day in coculture with astrocytes, microglia (red, ED-1) adopt a ramified morphology when in direct contact with astrocytes (A) while other microglia in the same culture not in contact with astrocytes remain round (B, arrow). N ote the large number of latex beads (green) phagocytosed by microglia not in contact with astrocytes. 
mediated factors play significant roles in regulating microglial phagocytosis $(26,67)$ in vitro, a phenomena that may be relevant to the turnover of SPs within the brain.

Several roles for microglia in the pathogenesis of AD have been proposed, including production of $A \beta$ fibrils $(16,71)$, proteolytic processing of $\beta P P(12)$, synaptic stripping (47), destruction of neurons through complement activation $(29,43,53)$, and the production of cytokines and neurotoxins $(2,25)$. Relatively little attention has been paid to phagocytic activities of microglia possibly because the ramified microglia associated with SPs, although activated $(34,41)$, are in a largely nonphagocytic state. Observations of minimal $A \beta$ phagocytosis in vivo (27) contrast with the robust debris removal capacity that microglia actually possess following traumatic injury such as a stroke or penetrating injury. I ndeed, following a stroke, microglia rapidly phagocytose SP in a rapid time frame consistent with our in vitro model (70). Significantly, both penetrating injury and stroke can lead to astrocyte death or migration from the immediate site of injury (40), which could, in turn, eliminate their regulatory role and allow for a more rapid rate of debris removal.

Our results are consistent with previous studies where dog microglia in culture (16) and rat microglia in situ phagocytosed SP cores (18). However, in both studies, the authors stressed the persistence of $A \beta$ rather than its removal and suggested that $A \beta$ was resistant to microglial proteases even though in the latter study $A \beta$ was present in small, intracellular vesicles. While we also found that some SP cores could persist for as long as 30 days in vitro, this represented only a small subpopulation of SP cores. Further, since the SP cores were initially of a uniform size, but once eaten, became incorporated into progressively smaller vesicles, we suggest that these observations are consistent with the idea that SP cores can be readily broken down by their host phagocyte $(3,57)$. The similar regulatory capacity of astrocytes on microglia in the presence of both SP cores and latex beads suggest astrocyte inhibition of microglial phagocytosis is not A $\beta$-specific. Astrocytes could regulate microglial phagocytosis through a number of possible mechanisms. Astrocytes could down-regulate microglial scavenger receptors or $(5,11,48)$ alter levels of phagocytosisrelated trophic factors (14). Alternatively, astrocytes may induce ramification which blocks the formation of pseudopods thought to be required for phagocytosis (59).

Although the specific astrocytic factor(s) that induce microglial ramification are unknown, a number of candidate molecules exist including MCSF 1 (39), fibronectin (10), and TGF - $\beta$ (66). In addition, a recent paper clearly implicated astrocytic extracellular matrix proteins (67) since fixed astrocyte monolayers as well as astrocyte matrix alone induced ramification. Our results are consistent with these findings, since astrocyte monolayers were much more effective than astrocyteconditioned media in suppressing phagocytosis. Although it is well established that astrocytes can induce ramification of microglia $(26,39,58,64)$, ours is the first to show that astrocytes concomitantly suppress microglial phagocytosis.

The implications for astrocyte regulation of microglial phagocytosis and debris removal within the CNS goes well beyond its potential role in AD. Following an injury to the PNS, macrophages rapidly adopt a round morphology and remove debris and necrotic tissue quickly $(7,20,51,72)$. In contrast, a lesion to the CNS such as severing $(7,50)$ or crushing (17) the optic nerve results in a much slower rate of resolution distally. Our data implicating astrocytes in the general suppression of microglial phagocytosis suggests that astrocytes may be indirectly responsible for the persistence of SP as well as other forms of debris in the brain.

\section{ACKNO WLEDG MENTS}

This work was supported by NIH Grants NS25713 and AG09287. D. DeWitt was also supported by predoctoral fellowship AG-0010511A1. The authors acknowledge S. L. Siedlack for assistance with SP isolation, J . Knez, and E. Medof for assistance with FACS sorting, R. Kalaria for the HLADR antibody used for immunostaining microglia in AD brain and P. Gambetti for helpful discussions.

\section{REFERENCES}

1. Abd-El-Basset, E., and S. Fedoroff. 1995. Effect of bacterial wall lipopolysaccharide (LPS) on morphology, motility and cytoskeletal organization of microglia in cultures. J. Neurosci. Res. 41: 222-237.

2. Araujo, D. M., and C. W. Cotman. 1992. $\beta$-Amyloid stimulates glial cells in vitro to produce growth factors that accumulate in senile plaques in Alzheimer's disease. Brain Res. 569: 141-145.

3. Ard, M. D., G. M. Cole, J . Wei, A. P. Mehrle, and J . D. Fratkin. 1996. Scavenging of Alzheimer's amyloid $\beta$-protein by microglia in culture. J . Neurosci. Res. 43: 190-202.

4. Ashwell, K. 1989. Development of microglia in the albino rabbit retina. J . Comp. Neurol . 287: 286-301.

5. Bell, M. D., R. Lopez-Gonzalez, L. Lawson, D. Hughes, I. Fraser, S. Gordon, and V. H. Perry. 1994. Upregulation of the macrophage scavenger receptor in responseto different forms of injury in the CNS. J . Neurocytol. 23: 605-613.

6. Berbel, P. and G. M. Innocenti. 1988. The development of the corpus callosum in cats: A light and electron-microscopic study. J . Comp. Neurol . 276: 132-156.

7. Bignami, A., R. Asher, and G. Perides. 1991. Brain extracellular matrix and nerve regeneration. Adv. Exp. Med. Biol. 296: 197-206.

8. Cai, X. D., T. E. Golde, and S. G. Younkin. 1993. Release of excess amyloid beta protein from a mutant amyloid beta protein precursor. Science 259: 514-516.

9. Canning, D. R., R. J . McKeon, D. A. DeWitt, G. Perry, J . Wujek, R. Fredrickson, and J . Silver. 1993. $\beta$-amyloid of Alzheimer's disease induces reactive gliosis that inhibits axon outgrowth. Exp. Neurol. 124: 289-298. 
10. Chamak, B., and M. Mallat. 1991. Fibronectin and Iaminin regulate the in vitro differentiation of microglial cells. Neuroscience 45: 513-527.

11. Christie, R. H., M. Freeman, and B. T. Hyman. 1996. Expression of the macrophage scavenger receptor, a multifunctional lipoprotein receptor, in microglia associated with senile plaques in Alzheimer's disease. Am. J . Pathol. 148: 399-403.

12. Cras, P., M. Kawai, S. Siedlak, P. Mulvihill, P. Gambetti, D. Lowery D. P. Gonzalez-DeWhitt, B. Greenberg, and G. Perry. 1990. Neuronal and microglial involvement in $\beta$-amyloid protein deposition in Alzheimer's disease. Am. J. Pathol. 137: 241-246.

13. Davis, E. J ., T. D. Foster, and W. E. Thomas. 1994. Cellular Forms and Functions of Brain Microglia. Brain Res. Bull. 34: 73-78.

14. Elkabes, S., E. M. DiCicco-Bloom, and I. B. Black. 1996. Brain microglia/macrophages express neurotrophins that selectively regulate microglia proliferation and function. J . Neurosci. 16: 2508-2521.

15. Ferrer, I., E. Bernet, E. Soriano, T. Del Rio, and M. Fonseca. 1990. Naturally occurring cell death in the cerebral cortex of the rat and removal of dead cells by transitory phagocytes. Neuroscience 39: 451-458.

16. Frackowiak, J ., H. M. Wisniewski, J. Wegiel, S. Merz, K. I qbal, and K. C. Wang. 1992. Ultrastructure of the microglia that phagocytose amyloid and the microglia that produce $\beta$-amyloid fibrils. Acta Neuropathol . 84: 225-233.

17. Frank, M., and H. Wolburg. 1996. Cellular reaction at the lesion site after crushing of the rat optic nerve. Glia 16: 227-240.

18. Frautschy, S. A., G. M. Cole, and A. Baird. 1992. Phagocytosis and deposition of vascular beta-amyloid in rat brains injected with Alzheimer beta amyloid. Am. J . Pathol . 140: 1389-1399.

19. Games, D., D. Adams, R. Alessandrini, R. Barbour, P. Berthe lette, C. Blackwell, T. Carr, J. Clemens, T. Donaldson, F. Gillespie, T. Guido, S. Hagopian, K. J ohnson-Wood, K. Khan, M. Lee, P. Leibowitz, I. Lieberburg, S. Little, E. Masliah, L. McConiogue, M. Montoya-Zavala, L. Mucke, L. Paganini, E. Penniman, M. Power, D. Schenk, P. Seubert, B. Snyder, F. Soriano, H. Tan, J. Vitale, S. Wadsworth, B. Wolozin, and J . Zhao. 1995. Alzheimer-type neuropathology in transgenic mice overexpressing V717F $\beta$-amyloid precursor protein. Nature 373: 523-527.

20. Gehrmann, J., and G. Kreutzberg. 1995. Microglia in experimental neuropathology. In Neuroglia $(\mathrm{H}$. Kettenman and B. Ransom, Eds.), pp. 885- 904. Oxford UP, New York.

21. Gehrmann, J., Y. Matsumoto, and G. W. Kreutzberg. 1995. Microglia: Intrinsic immunoeffector cell of the brain. Brain Res. Rev. 20: 269-287.

22. Giordana, M. T., A. Attanasio, P. Cavalla, A. Migheli, M. C. Vigliani, and D. Schiffer. 1994. Reactive Cell Proliferation and microglia following injury to the rat brain. Neuropathol. Applied Neurobiol. 20: 163-174.

23. Giulian, D., and T. J . Baker. 1986. Characterization of ameboid microglia isolated from developing mammalian brain. J . Neurosci. 6: 2163-2178.

24. Giulian, D., J. Chen, J. E. Ingeman, J. K. George, and M. Naponen. 1989. The role of mononuclear phagocytes in wound healing after traumatic injury to adult mammalian brain. J . Neurosci. 9: 4416-4429.

25. Giulian, D., L. J . Haverkamp, J . Li, W. L. Karshin, J . Yu, D. Tom, X. Li, and J. B. Kirkpatrick. 1995. Senile plaques stimulate microglia to release a neurotoxin found in Alzheimer's brain. Neurochem. Int. 27: 119-137.

26. Giulian, D., J. Li, S. Bartel, J. Broker, X. Li, and J. B. Kirkpatrick. 1995. Cell surface morphology identifies microglia as a distinct class of mononuclear phagocyte. J . Neurosci. 15: 7712-7726.

27. Hachimi, K. H. E., and J. F. Foncin. 1994. Do microglial cells phagocyte the $\beta / A 4$-amyloid senile plaque core of Alzheimer disease? C. R. Acad. Sci. III 317: 445-51.

28. Haga, S., K. Akai, and T. I shii. 1989. Demonstration of microglia cells in and around senile (neuritic) plaques in the Alzheimer brain: An immunohistochemical study using a novel monoclonal antibody. Acta Neuropathol . (Berlin) 77: 569-575.

29. Haga, S., K. Ikeda, M. Sato, and T. Ishii. 1993. Synthetic Alzheimer amyloid beta/A4 peptides enhance production of complement C3 component by cultured microglial cells. Brain Res 601: 88-94.

30. Hume, D. A., V. H. Perry, and S. Gordon. 1983. Immunohistochemical localization of a macrophage-specific antigen in developing mouse retina: phagocytosis of dying neurons and differentiation of microglial cells to form a regular array in the plexiform layers. J . Cell Biol. 97: 253-257.

31. Hyman, B. T., K. Marzl off, and P. V. Arriagada. 1993. Thelack of accumulation of senile plaques or amyloid burden in Alzheimer's disease suggests a dynamic balance between amyloid deposition and resolution. J. Neuropathol. Exp. Neurol. 52: 594-600.

32. Innocenti, G. M., H. Koppel, and S. Clarke. 1983. Transitory macrophages in the white matter of the devel oping visual cortex I. Light and electron microscopic characteristics and distribution. Brain Res. 313: 39-53.

33. Innocenti, G. M., S. Clarke, and H. Koppel. 1983. Transitory macrophages in the white matter of the developing visual cortex. II. Development and relations with axonal pathways. Brain Res. 313: 55-66.

34. Itagaki, S., P. L. McGeer, H. Akiyama, S. Zhu, and D. Selkoe. 1989. Relationship of microglia and Astrocytes to amyloid deposits of Alzheimer disease. J . Neuroimmunol . 24: 173-182.

35. Killackey, H. P. 1984. Glia and the elimination of transient cortical projections. Trends Neurosci. 7: 225-226.

36. Kim, K. S., D. F. Miller, V. J . Sapienza, C. J. Chen, C. Bai, I. Grundke-lqbal, J. R. Currie, and H. M. Wisniewski. 1988. Production and characterization of monoclonal antibodies reactive to synthetic cerebrovascular amyloid peptide. Neurosci. Res. Commun. 2: 121-130.

37. Lawson, L. J ., L. Frost, J . Risbridger, S. Fearn, and V. H. Perry. 1994. Quantification of the mononuclear phagocyte response to Wallerian degeneration of the optic nerve. J. Neurocytol. 23: 729-744.

38. Linden, R., L. A. Cavalcante, and P. C. Barradas. 1986. Mononuclear phagocytes in the retina of developing rats. Histochemistry 85: 335-339.

39. Liu, W., C. F. Brosnan, D. W. Dickson, and S. C. Lee. 1994. Macrophage colony-stimulating factor mediates astrocyteinduced microglial ramification in human fetal central nervous system culture. Am. J . Pathol. 145: 48-53.

40. Liu, X. Z., X. M. Xu, R. Hu, C. Du, S. X. Zhang, J. W. McDonald, H. X. Dong, Y. J. Wu, G. S. Fan, M. F. J acquin, C. Y. Hsu, and D. W. Choi. 1997. Neuronal and glial apoptosis after traumatic spinal cord injury. J . Neurosci. 17: 5395-5406.

41. Mackenzie, I. R., C. Hao, and D. G. Munoz. 1995. Role of microglia in senile plaque formation. Neurobiol. Aging 16: 797-804.

42. Mandybur, T.I., and C. C. Chuirazzi. 1990. Astrocytes and the plaques of Alzheimer's disease. Neurol ogy 40: 635-639.

43. McGeer, P. L., S. I tagaki, H. Tago, E. G. McGeer. 1987. Reactive microglia in patients with senile dementia of theAlzheimer type are positive for the histocompatibility glycoprotein HLA-DR. Neurosci. Lett. 79: 195-200. 
44. McMillian, M. K., L. Thai, J. S. Hong, J. P. O'Callaghan, and K. R. Pennypacker. 1994. Brain injury in a dish: A model for reactive gliosis. Trends Neurosci. 17: 138-142.

45. Milligan, C. E., T. J . Cunningham, and P. Levitt. 1991. Differential immunocytochemical markers reveal the normal distribution of brain macrophages and microglia in the developing rat brain. J . Comp. Neurol. 314: 125-135.

46. Naruse, S., S. Igarashi, H. Kobayashi, D. Aoki, T. Inuzuka, K. Kaneko, T. Shimizu, K. Iihara, T. Kojima, and Miyatake. 1991. Mis-sense mutation Val-Ile in exon 17 of the amyloid precursor protein gene in J apanese familial Alzheimer's disease. Lancet 337: 978-979.

47. Nieto-Sampedro, M., and F. Mora. 1994. Active microglia, sick astroglia and Alzheimer type dementias. Neuroreport 5: 375380.

48. Paresce, D. M., R. N. Ghosh, and F. R. Maxfield. 1996. Microglial cells internalize aggregates of the Alzheimer's disease Amyloid $\beta$-Protein via a scavenger receptor. Neuron 17: 553-565.

49. Perlmutter, L. S., S. A. Scott, E. Barron, and H. C. Chui. 1992. MHC class II-positive microglia in human brain: association with Alzheimer lesions. J . Neurosci. Res. 33: 549-558.

50. Perry, V. H., M. C. Brown, and S. Gordon. 1987. The macrophage response to central and peripheral nerve injury. A possible role for macrophages in regeneration. J . Exp. Med. 165: 1218-1223.

51. Perry, V. H., and S. Gordon. 1987. Macrophages and microglia in the nervous system. Trends Neuroci. 11: 273-277.

52. Pike, C. J., B. J. Cummings, and C. W. Cotman. 1995. Early association of reactive astrocytes with senile plaques in Alzheimer's disease. Exp. Neurol. 132: 172-179.

53. Rogers, J ., N. R. Cooper, S. Webster, J . Schultz, P. L. McGeer, S. D. Styren, W. H. Civin, L. Brachova, B. Bradt, P. Ward, and I. Lieberburg. 1992. Complement activation by $\beta$-amyloid in Alzheimer disease. Proc. Natl. Acad. Sci. USA 89: 10016-10020.

54. Rosana, G. R. and J. A. Swanson. 1996. Microtubules can modulate pseudopod activity from a distance inside macrophages. Cell Motil. Cytoskel eton 34: 230-245.

55. Selkoe, D. J. 1991. The molecular pathology of Alzheimer's disease. Neuron 6: 487-498.

56. Selkoe, D. J ., C. R. Abraham, M. B. Podlisny, and L. K. Duffy. 1986. I solation of low-molecular-weight proteins from the amyIoid plaque fibers in Alzheimer's disease. J . Neurochem. 46: 1820-1834.

57. Shaffer, L. M., M. D. Dority, R. Gupta-Bansal, R. C. A. Frederickson, S. G. Younkin, and K. R. Brunden. 1995. Amyloid $\beta$ protein $(A \beta)$ removal by neuroglial cells in culture. Neurobiol . Aging 16: 737-745.

58. Sievers, J., R. Parwaresch, and H. U. Wottge. 1994. Blood monocytes and spleen macrophages differentiate into microglialike cells on monolayers of Astrocytes: Morphology. Glia 12: 245-258.

59. Sternberger, L. A. 1986. Immunocytochemistry, 3rd ed. Wiley, New York.

60. Stoll, G., B. D. Trapp, and J. W. Griffin. 1989. Macrophage function during Wallerian degeneration of rat brain optic nerve: Clearance of degenerating myelin and Ia expression. J . Neurosci. 9: 2327-2335.

61. Streit, W. J. 1990. An Improved Staining Method for Rat Microglial Cells Using the Lectin from Griffonia simplicifolia (GSA I-B 4 ). J . Histochem. Cytochem. 38: 1683-1686.

62. Streit, W. J . 1995. Microglial Cells. In Neuroglia (H. Kettenman and B. Ransom, Eds.) pp. 885-904. Oxford UP, New York.

63. Streit, W. J . and G. W. Kreutzberg. 1988. Response of endogenous glial cells to motor neuron degeneration induced by toxin ricin. J . Comp. Neurol. 268: 248-263.

64. Suzuki, N., T. T. Cheung, X. D. Cai, A. Odaka, L. Otvos, C. Eckman, T. E. Golde, and S. G. Younkin. 1994. An increased percentage of Iong amyloid beta protein secreted by familial amyloid beta protein precursor (beta APP 717) mutants. Science 264: 1336-1340.

65. Suzumura, A., T. Marunouchi, and H. Yamamoto. 1991. Morphological transformation of microglia in vitro. Brain Res. 545: 301-306.

66. Suzumura, A., M. Sawada, and H. Yamamoto, and T. Marunouchi. 1993. Transforming Growth F actor- $\beta$ Suppresses Activation and Proliferation of microglia in vitro. J . Immunol. 151: 21502158.

67. Tanaka, J., and N. Maeda. 1996. Microglial ramification re quires nondiffusible factors derived from astrocytes. Exp. Neurol. 137: 367-375.

68. Thomas, W. E. 1992. Brain macrophages: evaluation of microglia and their functions. Brain Res. Rev. 17: 61-74.

69. Ward, S. A., P. A. Ransom, P. L. Booth, and W. E. Thomas. 1991. Characterization of ramified microglia in tissue culture: Pinocytosis and motility. J . Neurosci. Res. 29: 13-28.

70. Wisniewski, H. M., M. Barcikowska, and E. Kida. 1991. Phagocytosis of $\beta / A_{4}$ amyloid fibrils of the neuritic neocortical plaques. Acta Neuropathol. (Berlin) 81: 588-590.

71. Wisniewski, H. M., and J. Weigel. 1993. Migration of perivascular cells into the neuropil and their involvement in $\beta$-amyloid plaque formation. Acta Neuropathol . 85: 586-595.

72. Wood, G. W., K. A. Gollahon, S. A. Tilzer, T. Vats, and R. A. Morantz. 1979. The failure of microglia in normal brain to exhibit mononuclear phagocyte markers. J . Neuropathol. Exp. Neurol. 38: 369-376. 